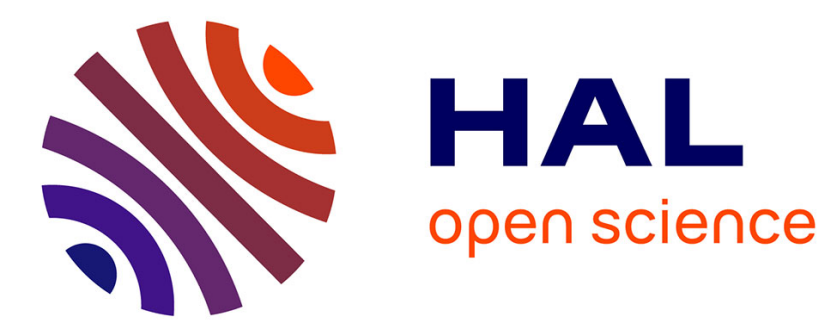

\title{
First Results Using Robust Controller Synthesis in Automatic Guided Vehicles Applications
}

Philippe Martinet, Christian Thibaud, Djamel Khadraoui, Jean Gallice

\section{To cite this version:}

Philippe Martinet, Christian Thibaud, Djamel Khadraoui, Jean Gallice. First Results Using Robust Controller Synthesis in Automatic Guided Vehicles Applications. IAV'98 - Third IFAC Symposium on Intelligent Autonomous Vehicles, Mar 1998, Madrid, Spain. pp.345-350, 10.1016/S14746670(17)44109-7 . hal-02465589

\section{HAL Id: hal-02465589 \\ https://hal.inria.fr/hal-02465589}

Submitted on 4 Feb 2020

HAL is a multi-disciplinary open access archive for the deposit and dissemination of scientific research documents, whether they are published or not. The documents may come from teaching and research institutions in France or abroad, or from public or private research centers.
L'archive ouverte pluridisciplinaire HAL, est destinée au dépôt et à la diffusion de documents scientifiques de niveau recherche, publiés ou non, émanant des établissements d'enseignement et de recherche français ou étrangers, des laboratoires publics ou privés. 


\title{
FIRST RESULTS USING ROBUST CONTROLLER SYNTHESIS IN AUTOMATIC GUIDED VEHICLES APPLICATIONS
}

\author{
Philippe Martinet, Christian Thibaud, \\ Djamel Khadraoui, Jean Gallice
}

\author{
Laboratoire des Sciences et Matériaux pour l'Electronique, \\ et d'Automatique. \\ Université Blaise Pascal de Clermont-Ferrand, \\ U.M.R. 6602 du C.N.R.S., F-63177 Aubière Cedex, France \\ E-Mail: Philippe.Martinet@lasmea.univ-bpclermont.fr \\ E-Mail: Christian.Thibaud@lasmea.univ-bpclermont.fr \\ E-Mail: Djamel.Khadraoui@lasmea.univ-bpclermont.fr \\ E-Mail: Jean.Gallice@lasmea.univ-bpclermont.fr \\ Tel: (33)-04-73-40-76-53, Fax: (33)-04-73-40-72-62
}

\begin{abstract}
We have been interested in Automatic Guided Vehicles (AGV) for several years. In this paper, we synthesize controllers for AGV applications. Particularly, we are interested in road following and direction change tasks, and in analyzing the influence of roll and pitch perturbations on vehicle behaviour. We use the bicycle as the kinematic vehicle model, and we choose the white band position of the road as the sensor signal. We define an interaction between the camera, which is mounted inside the vehicle, and the white band detected in the image space. Using this kind of interaction, we present how to use a pole assignment technique to solve the servoing task. We show the simulation and experimental results (1/10 scale demonstrator) with and without perturbations. Then, we investigate in robust controller to slow down the effect of perturbations on the vehicle behaviour.
\end{abstract}

Keywords: Visual servoing, robust control, mobile robot, vehicles, modelling, vision

\section{INTRODUCTION}

In the realm of intelligent systems for highways, development of AGV is necessary to enable vehicles to drive automatically along the road. In fact, the requirement is for a controller that can maintain the position and the orientation of the vehicle with respect to the centre of the road and/or apply changes of direction. The problem of vehicle control using a camera has been given considerable attention by many authors (Dickmanns and Zapp, 1987; Kehtarnavaz et al., 1991; Raymond and Chaouchi, 1994; Wallace et al., 1986; Waxman et al., 1987). The work described in (Jurie et al., 1992; Jurie et al., 1993; Jurie et al., 1994) is among the most notable in lateral control using monocular vision. It consists of the reconstruction of the road using the $2 \mathrm{D}$ visual information extracted from the image processing system (Chapuis et al., 1995). In recent years, the integration of computer vision in robotics has steadily progressed, from the early "look and move" systems, to current systems in which visual feedback is incorporated directly into the control loop. These techniques of vision based control are used to control holonomic robots in different domains (Feddema and Mitchell, 1989; Khadraoui et al., 1996; Papanikolopoulos et al., 1991; Papanikolopoulos et al., 1993). 
The principle of this approach is based on the task function approach (Samson et al., 1991), and many people have developed this concept applied to visual sensors (Chaumette, 1990; Espiau et al., 1992; Hutchinson et al., 1996). There are still few applications in mobile robots using this kind of approach. The main difficulty is due to the presence of nonholonomic mechanical connections which limit robot movements (Pissard-Gibollet and Rives, 1991).

We have proposed a new technique with a visual servoing approach, in which control incorporates the visual feedback directly (Khadraoui et al., 1995; Martinet et al., 1997). In other words, this is specified in terms of regulation in the image frame of the camera. Our application involves controlling the lateral road position of a vehicle following the motorway white line. A complete 2D model of both the vehicle and the scene is then essential. It takes into account the visual features of the scene and the modelling of the vehicle.

The main purpose of this study is the development of a new lateral control algorithm. We propose a new control model, based on state space representation, where the elements of the state vector are represented by the parameters of the scene, extracted by vision. Then, we use robust control approach to improve the vehicule behaviour when we introduce perturbations in the closed loop. These approaches were experimented with a $1 / 10$ scale demonstator. It is composed of a cartesian robot with 6 degrees of freedom (built by the firm AFMA Robot) and the parallel vision system WINDIS (Martinet et al., 1991; Rives et al., 1993). This whole platform is controlled by a VME system, and can be programmed in $\mathrm{C}$ language under the VxWorks real time operating system. The CCD camera is embedded on the end effector of the cartesian robot and is connected to the vision system WINDIS. The road, built to a $1 / 10$ scale, comprises three white lines. For each level of this vision system, we introduced parallelism allowing us to reach video rate for most of the application tasks. The vision system computes the $(a, b)$ parameters of the projected line in image plane at video rate. In this implementation, we have identified a data flow latency of three sample periods.

\section{MODELLING ASPECT}

Before synthesizing the control laws, it is necessary to obtain the model of the vehicle and the one which expresses the interaction between the sensor and the environment. We just indicates the main results of modelling aspect presented in (Martinet et al., 1997)
It is useful to approximate the kinematic of the steering mechanism by assuming that the two front wheels turn slightly differentially. Then, the instantaneous center of rotation can be determined purely by kinematic means. This amounts to assuming that the steering mechanism is the same as that of a bicycle. Let the angular velocity vector directed along $z$ axis be called $\dot{\psi}$ and the linear one directed along $x$ axis called $\dot{x}$.

The approximation to small angles gives us the relation between the differential of the lateral coordinate $x$ and the lateral deviation $\psi$ with regard to $\delta$, expressed as follows:

$$
\left\{\begin{array}{l}
\dot{x}=-V \psi \\
\dot{\psi}=\frac{V}{L} \delta
\end{array}\right.
$$

The scene consists of a $3 D$ line and its projected image is represented by a $2 D$ line (Chapuis et al., 1995).

The equation of the line expressed in the image frame is given by the following relation:

$$
X=a Y+b
$$

where $(a, b)$ are the line parameters expressed by:

$$
\left\{\begin{array}{l}
a=\frac{f_{x} x}{f_{y} h} \\
b=f_{x}\left(\frac{\alpha x}{h}+\psi\right)
\end{array}\right.
$$

and:

- $h$ is the camera height

- $\alpha$ is the inclination angle of the camera

- $\psi$ is the orientation of the vehicle

- $f_{x}$ and $f_{y}$ are the intrinsic parameters of the camera

\section{CONTROL ASPECT}

In this section, we show how to synthesize controllers. First, we establish the state equation of the system, and we define a controller with a pole assignment technique and different characteristics. We verify by simulation the system behaviour without perturbations. We then introduce some perturbations, and analyse the simulation and experimental results.

Secondly, we use robust controller synthesis to improve the ouput behaviour and the vehicle behaviour. Many authors, like (Banyaz and Keviczky, 1996; Carabelli and Malan, 1996; Doyle et al., 1989; Dorato and Li, 1986), have contributed to developp this approach. (Byrne and Chaouki, 1994) has applied this technique to the Lateral Control of Vehicles. 


\subsection{Pole assignment approach}

\subsubsection{Controller design}

Here, we present the application of the pole assignment technique when the state model is expressed directly in the sensor space. In our case, the sensor space is the image plane. The controller design is based on the kinematic model of the vehicle. We use the $(a, b)$ parameters of the $2 D$ line in the image plane as the state vector. We drive the vehicle with the action on the wheel angle $\delta$. We choose $b$ as the ouput parameter of the system and use the results of the vehicle and scene modellings to obtain the following equation:

$$
\left\{\begin{array}{l}
-V \psi=\xi_{1} \dot{a} \\
(V / L) \delta=\xi_{2} \dot{a}+\xi_{3} \dot{b}
\end{array}\right.
$$

The state vector, denoted by $\underline{s}=(a, b)^{T}$, is equal to the sensor signal vector in the state space representation. Developing, we have the following state model of the system:

$$
\left\{\begin{array}{l}
\dot{\dot{s}}=A \underline{s}+B \delta \\
b=C \underline{s}
\end{array}\right.
$$

We introduce an integrator into the control law in order to eliminate the static error in case of perturbations. The visual servoing scheme is presented by the figure 1 .

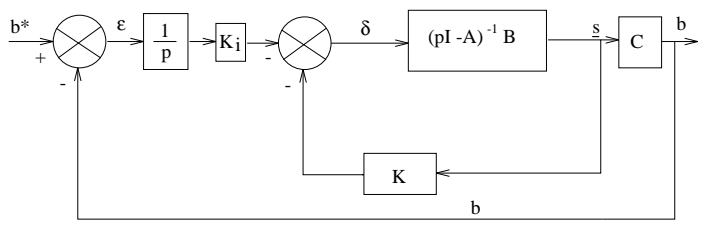

Fig. 1. Visual servoing scheme with integrator

In this case, we can express the control law by the relation:

$$
\delta=-k_{1} a-k_{2} b-K_{i} \int\left(b^{*}-b\right) d t
$$

where $k_{1}, k_{2}$ and $k_{i}$ are the gains of the control law obtained by identifying the system to a third order system characterized by the following characteristic equation: $\left(p^{2}+2 \xi \omega_{0} p+\omega_{0}^{2}\right)\left(p+\xi \omega_{0}\right)$.

\subsubsection{Simulation and Experimental results}

To validate this control law, we use a simulator developed with Matlab. We use the kinematic model of the vehicle to simulate the behaviour of the vehicle, and the perspective projection relation to obtain the sensor signal $\underline{s}=(a, b)^{T}$. The first results (see figure 3 ) illustrate the output behaviour of the system corresponding to an input value $b^{*}=100$ pixels. We take into account a data flow latency (three sample periods) in all simulation tests. This was identified on our experimental site.

We chose $\omega_{0}=2 r d / s$ and $\xi=0.9$ in order to fix the behaviour of the system.

We introduce some perturbations in the $\alpha$ angle (from $\alpha=-5$ to $\alpha=-10$ ). In fact, no static error persists during servoing, but some oscillations and problems of stability appear when $\alpha$ is far from the reference value of $\alpha(-7$ degrees $)$. The corresponding experimental results take place in right of the figure 3 and confirm the simulation trends.

\subsection{Robust Control approach}

\subsubsection{Controller design}

Here, we present the application of the robust control technique, particularly in $H_{\infty}$ space.

The visual servoing scheme is presented by the figure 2 .

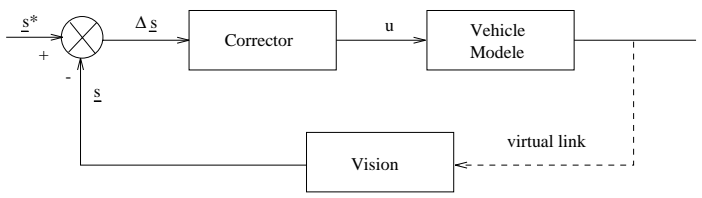

Fig. 2. Visual servoing scheme in $H_{\infty}$ space

We consider an additive perturbations in frequency domain :

$$
F(p)=F_{0}(p)+\Delta F(p)
$$

The aim is to determine a single robust controller $c(p)$ which insures the stability of the closed loop system. $c(p)$ insures the stability of $F_{0}(p)$. If the following condition is verified :

$$
|\Delta F(j \omega)| \leq|r(j \omega)| \quad \forall \omega
$$

then we can can express the robust stability condition as (Kimura, 1984) :

$$
\|u(p)\|_{\infty}=\|q(p) r(p)\|_{\infty}<1
$$

In theses conditions, the robust controller can be expresses by :

$$
\left\{\begin{array}{l}
q(p)=\frac{u(p)}{r(p)} \\
c(p)=\frac{q(p)}{1-F_{0}(p) q(p)}
\end{array}\right.
$$

Considering $\mathrm{b}$ parameter as the oupput of the system, we define :

$$
\left\{\begin{array}{l}
F_{0}(p)=b / \delta=\left(V^{2} \xi_{2}+p \xi_{1} V\right) /\left(\xi_{1} p^{2} L \xi_{3}\right) \\
\frac{\Delta F(p)}{F_{0}(p)}=\frac{V \Delta \xi_{2}+p \Delta \xi_{1}}{V \xi_{2}+p \xi_{1}}+\frac{\Delta \xi_{1}}{\xi_{1}}
\end{array}\right.
$$


with : $\Delta \xi_{2}=-\Delta \alpha f_{y} / f_{x}$ and $\Delta \xi_{1}=\Delta h f_{y} / f_{x}$

Using the following expression of $r(p)$ :

$$
r(p)=\sup _{\omega}\left|\frac{\Delta F(j \omega)}{F_{0}(j \omega)}\right| F_{0}(p)
$$

and after some developments, we obtain the robust controller $c(p)$ :

$$
\frac{K \xi_{1} L \xi_{3} p^{2}\left(p+p_{1}\right)}{V\left(p \xi_{1}+V \xi_{2}\right)\left[p^{3}+p^{2} \lambda_{1}+p \lambda_{2}+\lambda_{3}\right]}
$$

\subsubsection{Simulation and experimental results}

As for the pole assignment technique, we have developped a simulator in matlab. We introduce perturbations on $\alpha$ angle (from $\alpha=-3$ to $\alpha=$ -10) during simulation. Figure 4 shows the simulation and experimental results of robust control approach using b parameter as the output of the system. There is no static error during servoing and the stability is well improved.

If we look at figure 5 , we can compare the behaviour of the lateral position of the vehicle. In left, we have the behaviour when we use the pole assignment technique, and in right the one corresponding to robust control technique. We conclude that the behaviour is more stable with robust controller, but we observe a constant offset in the lateral position depending on the $\alpha$ angle variation.

To solve this problem, we use the $a$ parameter of the line as the output of the system, to synthesize a new robust controller using the $H_{\infty}$ technique. The experimental results are presented in figure 6 . It illustrates the ouptut behaviour of the system corresponding to an input value $a^{*}=0.4$ and the behaviour of the lateral position. As we can see, there is no static error in the output response and no offset in the lateral position when we introduce perturbations on $\alpha$ angle.

\section{CONCLUSION AND FUTURE WORK}

Controllers based on a visual servoing approach, have been developed in this paper. We designed a controller with a pole assignment technique directly in the image space. After modelling the vehicle and the scene, we obtained equations which can be used to write the state model of the system. Visual servoing is performed well when there are no perturbations. When perturbations occur, a static error and oscillations appear. By introducing an integrator into the visual servoing scheme, we suppress the static error but amplify the oscillation problem.
Then, we investigate a robust control approach. The choice of $b$ as the ouput parameter of the system does not permit the control of the lateral position of the vehicle precisely when the perturbations appear, but insure a heading control. The choice of $a$ parameter as the output of the system, to synthesize a new robust controller, seems to be good enough when we have perturbations on $\alpha$ angle. In the future, we will investigate a controller which can take into account a combination of perturbations on $\alpha$ angle and perturbations on camera height. We assume that experimentation on a real vehicle will be necessary to validate all of the primary results presented in this paper.

\section{REFERENCES}

Banyaz, C.S. and L. Keviczky (1996). $\mathrm{H}_{\infty}$ criteria in frequency domain. In: Proceedings of The World Congress - IAC. Vol. 4. Montpellier, France. pp. 41-47.

Byrne, R.H. and A. Chaouki (1994). Robust lateral control of highway vehicles. In: Proceedings of Intelligent Vehicle Symposium. Paris, France. pp. 375-380.

Carabelli, S. and S. Malan (1996). Low order $\mathrm{h}_{\infty}$ controller design for a magnetic ball levitator. In: Proceedings of The World Congress - IAC. Vol. 4. pp. 101-106.

Chapuis, R., A. Potelle, J.L. Brame and F. Chausse (1995). Real-time vehicle trajectory supervision on the highway. The International Journal of Robotics Research 14(6), 531-542.

Chaumette, F. (1990). La relation vision commande: théorie et application à des tâches robotiques. PhD thesis. IRISA/INRIA. Rennes, France.

Dickmanns, E.D. and A. Zapp (1987). Autonomous high speed road vehicle guidance by computer. In: Proceedings of 10th IFAC World Congress.

Dorato, P. and Yunzhi Li (1986). A modification of the classical Nevanlinna-pick interpolation algorithm with applications to robust stabilization. IEEE Transactions on Automatic Control 31(7), 645-648.

Doyle, J., K. Glover, P. Khargonekar and B. Francis (1989). State space solutions to standard $\mathrm{h}_{2}$ and $\mathrm{h}_{\infty}$ control problems. IEEE Transactions on Automatic Control.

Espiau, B., F. Chaumette and P. Rives (1992). A new approach to visual servoing in robotics. IEEE Transactions on Robotics and Automation 8(3), 313-326.

Feddema, J. T. and O. R. Mitchell (1989). Visionguided servoing with feature-based trajectory generation. IEEE Transactions on Robotics and Automation 5(5), 691-700. 
Hutchinson, S., G.D. Hager and P. Corke (1996). A tutorial on visual servo control. IEEE Transactions on Robotics and Automation 12(5), 651-670.

Jurie, F., P. Rives, J. Gallice and J.L. Brame (1992). A vision based control approach to high speed automatic vehicle guidance. In: Proceedings of IARP Workshop on Machine Vision Applications. Tokyo, Japan. pp. 329333.

Jurie, F., P. Rives, J. Gallice and J.L. Brame (1993). High speed automatic vehicle guidance based on vision. In: Proceedings of Intelligent Autonomous Vehicle. Southampton, United Kingdom. pp. 205-210.

Jurie, F., P. Rives, J. Gallice and J.L.Brame (1994). High-speed vehicle guidance based on vision. Control Engineering Practice 2(2), 287-297.

Kehtarnavaz, N., N.C. Grisworld and J.S. Lee (1991). Visual control for an autonoumous vehicle (bart)-the vehicle following problem. IEEE Transactions on Vehicular Technology 40(3), 654-662.

Khadraoui, D., G. Motyl, P. Martinet, J. Gallice and F. Chaumette (1996). Visual servoing in robotics scheme using a camera/laser-stripe sensor. IEEE Transactions on Robotics and Automation 12(5), 743-749.

Khadraoui, D., P. Martinet and J. Gallice (1995). Linear control of high speed vehicle in image space. In: Proceedings of Second International Conference on Industrial Automation. Vol. 2. IAIA. Nancy , France. pp. 517-522.

Kimura, H. (1984). Robust stabilization for a class of transfer fonction. IEEE Transactions on Automatic Control 29, 788-793.

Martinet, P., D. Khadraoui, C. Thibaud and J. Gallice (1997). Controller synthesis applied to automatic guided vehicle. In: Proceedings of Fifh Symposium on Robot Control. SYROCO. Nantes, France.

Martinet, P., P. Rives, P. Fickinger and J.J. Borrelly (1991). Parallel architecture for visual servoing applications. In: Proceedings of the Workshop on Computer Architecture for $\mathrm{Ma}$ chine Perception. Paris, France. pp. 407-418.

Papanikolopoulos, N., P.K. Khosla and T. Kanade (1991). Vision and control techniques for robotic visual tracking. In: Proceedings of the IEEE International Conference on Robotics and Automation. Sacramento - USA.

Papanikolopoulos, N., P.K. Khosla and T. Kanade (1993). Visual tracking of a movinf target by a camera mounted on a robot: a combination of control and vision. IEEE Transactions on Robotics and Automation 9(1), 14-35.

Pissard-Gibollet, R. and P. Rives (1991). Asservissement visuel appliqué à un robot mobile: état de l'art et modélisation cinématique.
Technical Report 1577. Rapport de recherche INRIA.

Raymond, H.B. and A. Chaouchi (1994). Robust lateral control of highway vehicles. In: Proceedings of the Intelligent Vehicles '94 Symposium. Paris, France.

Rives, P., J.L. Borrelly, J. Gallice and P. Martinet (1993). A versatile parallel architecture for visual servoing applications. In: Proceedings of the Workshop on Computer Architecture for Machine Perception. News Orleans, USA. pp. 400-409.

Samson, C., M. Le Borgne and B. Espiau (1991). Robot Control: The task function approach. ISBN 0-19-8538057. Oxford University Press.

Wallace, R., K Matsuzak, Y. Goto, J. Crisman, J. Webb and T. Kanade (1986). Progress in robot road following. In: Proceedings of the IEEE International Conference on Robotics and Automation.

Waxman, A.M., J. LeMoigne, L.S Davis, B. Srinivasan, T.R. Kushner, E. Liang and T. Siddalingaiah (1987). A visual navigation system for autonomous land vehicles. IEEE transactions on Robotics and Automation 3(2), 124141 . 

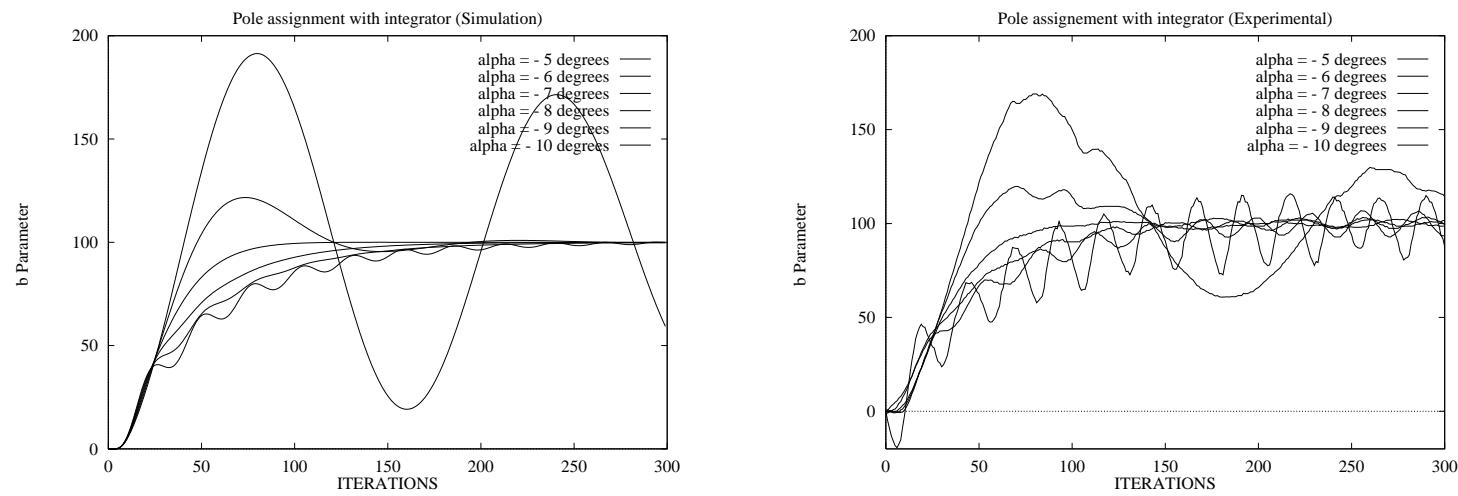

Fig. 3. Pole assignment approach: $b$ Output behaviour ( $\alpha$ from -6 to -10 degrees)
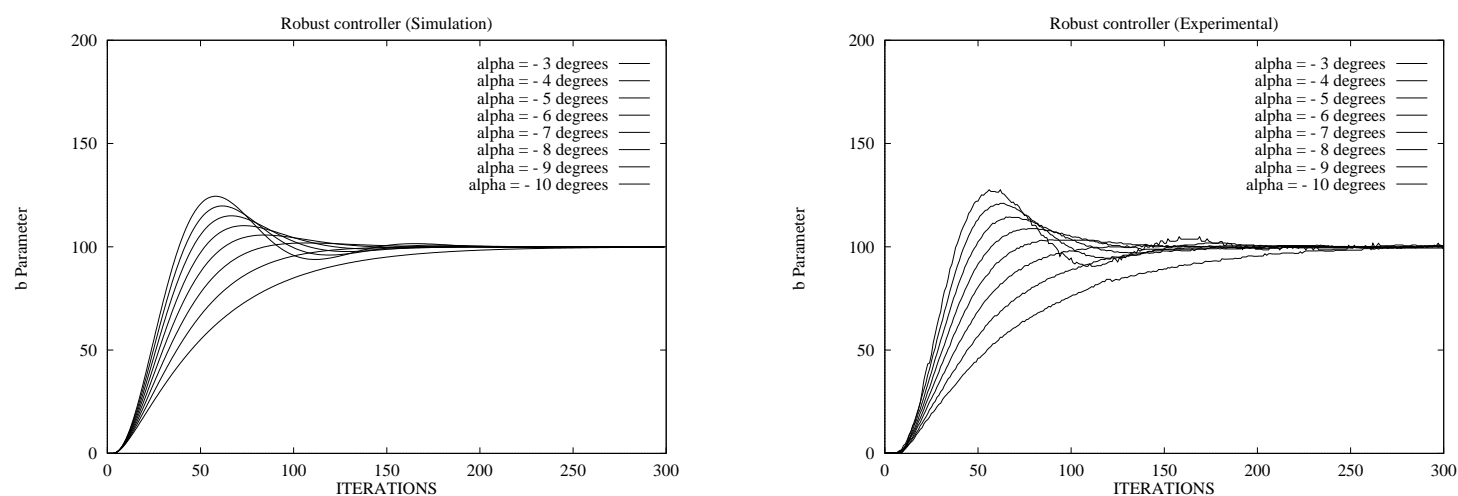

Fig. 4. Robust control approach: $b$ Output behaviour ( $\alpha$ from -3 to -10 degrees)
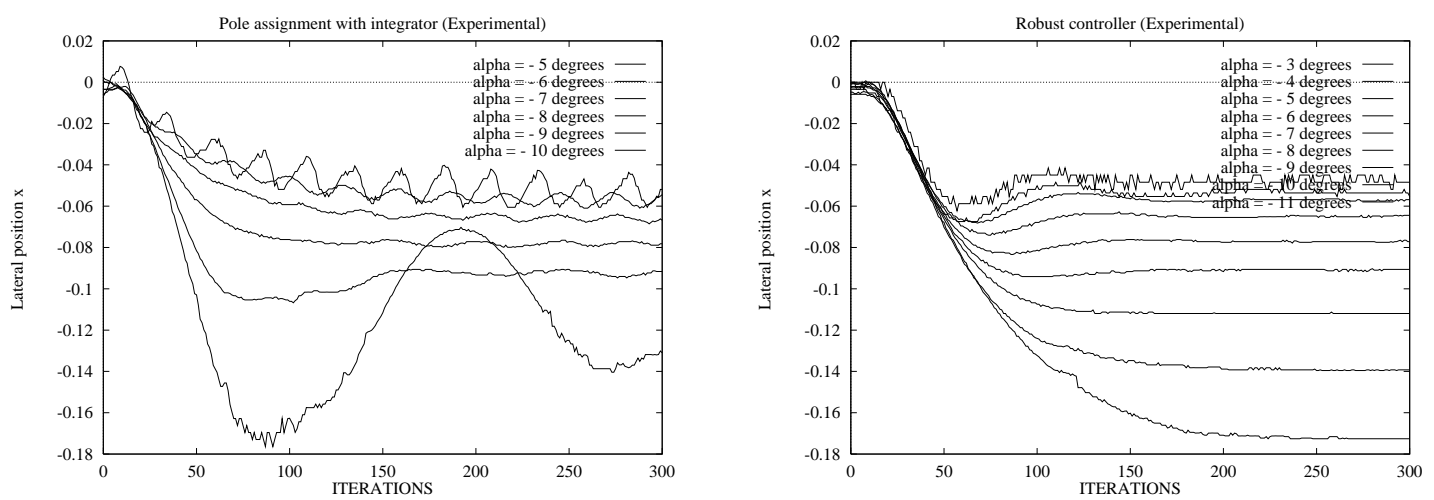

Fig. 5. Lateral position behaviour (Pole assignment and robust control approach)
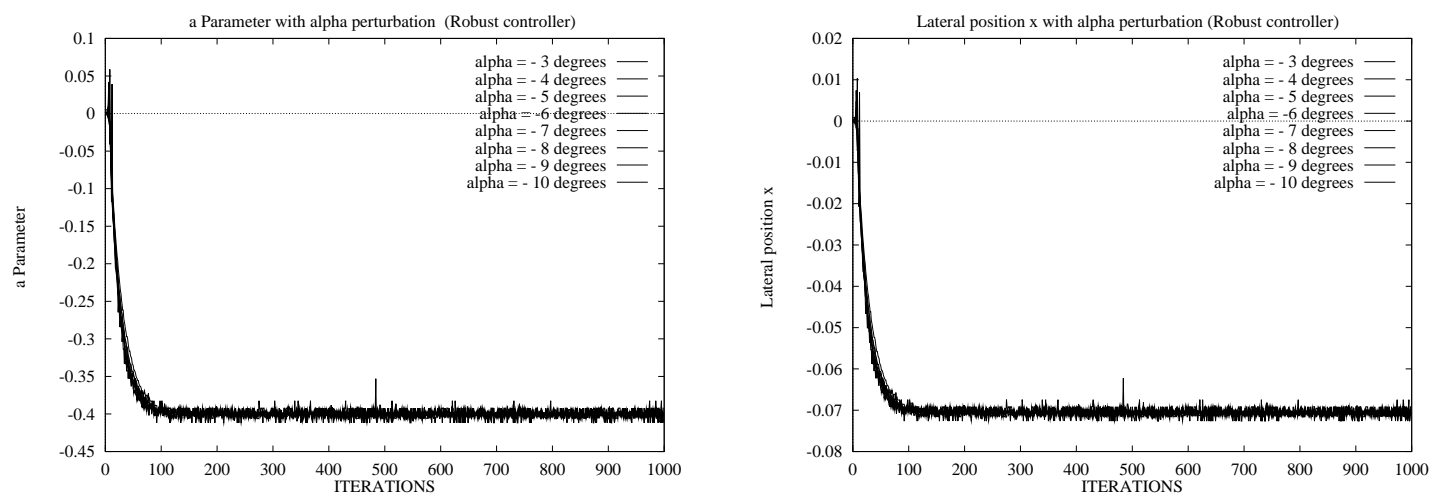

Fig. 6. a Parameter and lateral position behaviour with alpha perturbation (Robust control approach) 